\title{
O BEIJO SUBVERSIVO QUE SUBVERTE A TELINHA
}

Tânia Montoro \& Maria Luiza Mendonça

\begin{abstract}
Resumo
A ficção seriada televisiva, a telenovela, um gênero folhetinesco e com muito sucesso no Brasil, tem possibilitado uma autonomia para a indústria nacional do audiovisual, uma vez que a TV brasileira produz a maior parte da programação exibida em horário nobre (20 às 22 horas). Desde a década de 70, passou a exportar telenovelas para países dos cinco continentes incluindo latinos americanos e países socialistas. A persistência de elementos da cultura popular e a presença de elementos narrativos originários de formas reconhecidas, como a literatura de cordel, teatro de revista, as radionovelas e os romances modernos tem feito o sucesso da telenovela na cultura do cotidiano brasileiro e de outros países. Este artigo demostra, por meio da análise da circulação e consumo do audiovisual, dentro de uma perspectiva dos estudos culturais e estudos feministas e de gênero, as polemicas mediáticas com relação à representação de gênero particularmente da sexualidade na velhice feminina com a criação de tramas e personagens que assumem a homossexualidade, o lesbianismo, a bissexualidade e mesmo, ao deslocar conteúdos que pertenciam à esfera privada para o domínio público e operam também em sentido inverso, saturam o espaço público temas restritos à intimidade.
\end{abstract}

\section{PaLAVRas-chave}

Estudos de gênero; televisão; telenovela; representação audiovisual

\section{INTRODUÇÃO}

Este artigo é parte da pesquisa Narrativas audiovisuais e processos sócio- culturais e mediáticos, que se desenvolve na linha de pesquisa em Imagem, som e escrita, e se constitui em um grupo de investigação de professores, mestrandos e doutorandos do Programa de Pós Graduação em Comunicação da Universidade de Brasília — UnB e da Universidade Federal de Goiás — UFG, situadas no Centro Oeste brasileiro.

Ancorando suas preocupações na estreita relação que se estabelece entre representação imagética e construção e configuração de imaginários, a pesquisa tem como objetivo central analisar a representação imaginária da velhice e dos envelhecimentos na narrativa audiovisual contemporânea, problematizando essas singularidades nas construções da(s) identidade(s) de gênero. Uma gama de teses, artigos científicos, resenhas, ensaios tem sido produzido e está disponível no banco de dados do Conselho Nacional de Desenvolvimento Científico e Tecnológico(CNPq).

A velhice e os processos de envelhecimentos são questões universais que perpassam as condições sociais e culturais de todas as sociedades. Entretanto a velhice feminina tem significados específicos e individuais que impedem qualquer homogeneização desta faixa etária (Beauvoir, 1990; Bosi, 1987; Butler, 2003). O audiovisual é um dos principais difusores de transformações de comportamentos das sociedades contando 
com grande capacidade de abrangência temática e de simulação de realidades por meio de imagens e sons em movimento (Aumont, 2004; Burch, 2006).

Partindo destas premissas e considerando que a narrativa ficcional seriada contemporânea tem sido marcada por realizações audiovisuais que entrecruzam intimidade e cotidiano, temporalidades e subjetividades, as vivências dos processos de envelhecimentos tomaram visibilidades em parte das tramas dos folhetins eletrônicos; o que possibilitou a aproximação entre espectadores e personagens. "A análise destes produtos narrativos audiovisuais é uma oportunidade privilegiada para refletirmos sobre a sociedade como um todo, seja do ponto de vista global ou nacional, cultural, pessoal ou mercadológico" (Caldas \& Montoro, 2006, p. 157).

Como um sistema de representação a narrativa audiovisual constitui "uma atividade que constrói significados por meio da materialidade das imagens e sons" (Montoro, 2009, p.19). Este sistema de representação nos ajuda a conferir sentido à nossa experiência, auxilia no processo de construção identitária e nos ajuda a transitar pelas complexas redes contemporâneas de instituições, papéis e subjetividades.

As imagens, representações esparsas e fragmentadas da totalidade social acabam construindo um todo coerente — o imaginário social — por meio do qual nós percebemos os "mundos", as "realidades vividas" dos outros e, imaginariamente, reconstruímos as suas vidas e as nossas, de modo inteligível, dentro de uma totalidade vivida e vivenciada (Montoro, 2006, p.19).

Examinar a construção de identidades de gênero dentro da narrativa seriada ficcional da televisão brasileira, particularmente, no estudo das telenovelas brasileiras premiadas mundo afora, distribuídas e vendidas para mais de 40 países, nos oferece a possibilidade de tomar o espaço da visualidade em sua intimidade, nos dramas e nas tramas das historias das heroínas e vilões de um país desigual, múltiplo, sensual, que transita entre o urbano e rural que ancora na diversidade seu maior patrimônio imaterial.

As telenovelas têm constituído um importante material para os estudos das ciências da comunicação e cultura em função de ser um campo aberto para a compreensão de como as subjetividades são construídas e apresentadas ao telespectador, Para além de seu valor artístico, ligado à dramaturgia, tal como o teatro, o cinema e outras manifestações a telenovela constitui uma ferramenta de criação e transmissão de crenças e costumes, de normas, de modos de ser e de viver, de um ethos, portanto.

Moldada pela visão da classe média, a telenovela é responsável por trazer novidades às casas dos telespectadores que não possuem outras formas de entretenimento além de ser um retrato - nem sempre fiel — da sociedade, fortemente influenciada pela cultura de massa. Para Daniela Jakubaszko (2010, p. 15):

... o processo de aceitação da telenovela enquanto objeto de estudo cientifico se fez de modo bastante lento e repleto de desafios, conflitos e controvérsias. Romper com o pensamento predominante de que ela seria um produto de pouca importância, menor em termos artísticos, e quase sempre descrito como alienante, foi a tarefa de muitos estudos a ela dedicados. 
(...) Pode-se dizer hoje, que já existe no meio acadêmico consenso sobre a relevância e a necessidade de empreender, das mais diversas formas, investigações acerca da produção, circulação e recepção e consumo das telenovelas. Não é mais possível negar a influencia e a penetração deste produto na vida cotidiana dos brasileiros e latino americanos.

A família brasileira vem passando por transformações singulares ao longo das últimas três décadas requerendo que, no plano jurídico e legal não exista um sentido unívoco acerca do que é família. Amazonas e Braga (2006 apud Scorsolini-Comin \& Santos, 2012) referem-se a uma trans-historicidade do laço familiar, conceito que traz a ideia de movimento e dos processos de constante reconstrução da família, em oposição a uma noção cristalizada de família como algo eterno e referente de um único modelo. Entre os fatores que têm contribuído para essas transformações, podemos elencar as transições de ordem cultural, econômica, politica, e social, que tem mobilizado reflexões contemporâneas e torno do parentesco, dos diferentes arranjos familiares, bom como das rupturas e das redefinições dos papéis parentais e de gênero.

\section{UM POUQUINHO DA TELENOVELA BRASILEIRA}

Na década de 1970, a televisão brasileira começou a exibir seus programas a cores, com a telenovela $O$ bem amado. Em 1971, a Rede Globo instala seu departamento de marketing e cinco anos depois, a telenovela brasileira Gabriela baseada no livro do escritor baiano Jorge Amado dá inicio a exportações e prêmios internacionais. Quando foi exibida em Portugal, tal produção e mobilizou a imaginação dos portugueses que saíam de um isolamento imposto por um regime totalitário. Só a titulo de ilustração esta telenovela foi sucesso em países latino-americanos e do bloco socialista como Cuba, União Soviética e China.

Apesar da censura sobre os meios de comunicação no Brasil, durante a ditadura militar, proibindo inteiramente telenovelas gravadas e finalizadas de serem exibidas ao público, como Roque Santeiro (1975) ou Despedida de Casado (1974), vale salientar que as telenovelas percorreram uma trajetória de liberalização na maneira de representar relações amorosas, o papel da mulher, as mudanças na estrutura familiar. A temporalidade do folhetim eletrônico - gravado e assistido diariamente - faz com que ele se deixe penetrar em alguns improvisos que, de certa forma, é componentes de sua linguagem estrutural. Colado no cotidiano, o folhetim se estrutura a partir de uma continuidade não de uma coincidência - temporal entre os universos diegéticos e extradiegéticos, abarcando telespectadores e autores.

O telespectador acompanha o desenrolar lento e repetitivo e os saltos repentinos sem necessariamente assistir todos os capítulos. Ele, ou ela, os filhos e amigos torcem por determinados desdobramentos para o drama de certos personagens, comentam com os colegas de trabalho e informa-se sobre os futuros capítulos na imprensa especializada. Acompanhar ou assistir a uma telenovela é incorporar a trama ao cotidiano e de certa forma participar da dinâmica social que vai definindo os rumos da narrativa. 
Dessa forma, o telespectador anônimo está incorporado à dinâmica do fazer a telenovela, uma vez que eventualmente participam como telespectadores privilegiados militantes de movimentos sociais, políticos e empresários, fãs que tornam suas opiniões públicas por meio de pronunciamentos na imprensa, ações noticiadas e nas redes sociais que tomamos para exemplificar o movimento mobilizador que esta comunicação produz.

Com bases em pesquisas de audiência, perfil de público e grupos de discussões as emissoras brasileiras de televisão, particularmente, a rede Globo de televisão, pesquisam hábitos cotidianos de cidadãos, consumidores, telespectadores em potencial. $\mathrm{A}$ experiência acumulada ao longo dos anos gerou um conhecimento detalhado dentro do escopo da teoria da recepção - de que os telespectadores são ativos interpretes do que veem, em ultima instancia detentores do poder de criar e aniquilar vínculos de lealdade com segmentos específicos do público'.

Para criar e manter uma audiência fiel, a rede Globo gerou uma rotina complexa de procedimentos de pesquisa que alimenta uma interlocução. Informações recolhidas com os telespectadores por meio de grupos de discussão geram respostas como novidades na programação e spin offs ${ }^{2}$ capazes de surpreender, cativar e estimular a repercussão. No caso das telenovelas, novidade significa apresentar novos cenários, moda, trilhas sonoras, inovações tecnológicas e "temas polêmicos". E podemos afirmar que a homossexualidade é um destes temas, porque de forma embrionária desde a década de 80 , o assunto começa a aparecer nas tramas das telenovelas. De forma velada, somente como um índice, como forma de tangenciar a questão.

A denominada — telenovela das oito — da rede Globo de televisão veiculada em todo vasto território nacional é um hábito de consumo cultural e audiovisual totalmente incorporado ao comportamento cotidiano dos brasileiros. Decorre daí a relevância em examinar a forma como a televisão vem sendo incorporada no cotidiano das pessoas e como o cotidiano vem sendo revelado e incorporado a televisão com intuito de identificar personagens e sistemas de representação de normatização tomando uma programação específica (um canal de TV) e um produto audiovisual singular a (telenovela brasileira contemporânea), em sua relação com o universo simbólico das questões amplas dos estudos culturais e estudos feministas de cinema e televisão.

As análises das narrativas audiovisuais de conteúdo e consumo oferecem um mapa cognitivo que orientam um horizonte teórico e metodológico, um mergulho que nos permite formular uma cartografia de significados e uma topografia do sistema representacional considerando as audiovisualidades como protagonistas da cena midiática cotidiana e contemporânea. Nesta perspectiva e dentro de um marco de estudos da recepção dos produtos mediáticos contemporâneos que associados, a emergência de sujeitos, subjetividades, contextos e história passam a indicar possibilidades de significação.

Concebendo a imagem audiovisual no sentido proposto por Aumont (1995, p. 24) como aquela imagem delimitada por um quadro — o espaço da tela da televisão (mesmo

\footnotetext{
' Acerca da teoria da recepção, ver Hall (2003).

2 Spin offs são produtos como livros, CDs, peças de roupa, cards, videogames, blogs, etc, veiculado em uma mídia, mas que replica em outras.
} 
com a limitação de suporte, por ser a tv uma tela doméstica, ela mobiliza imaginários — um campo que nos transmite a ilusão de toda imagem), a análise empreendida tem como objeto refletir sobre algumas questões que estão mobilizando ${ }^{3}$ corações e mentes no Brasil, e fora dele, a partir da telenovela Babilônia, que vem produzindo sentidos pelos media, com disputa de fixação de significados sociais e legítimos. Dessa forma, busca-se identificar as controvérsias e polêmicas que circulam na recepção de dois temas controversos e singulares: o envelhecimento e a orientação sexual.

\section{SEXUALIDADES E ENVELHECIMENTOS MOBILIZAM REDES SOCIAIS}

Por intermédio da observação de postagens nas redes sociais, em especial no Facebook e em sítios especializados em noticiários sobre atores e "celebridades" durante a última semana de abril, pretende-se acompanhar e questionar a polarização das manifestações públicas acerca da nova novela exibida pela Rede Globo no horário "nobre" (21 horas), Babilônia, do experiente diretor e ator Denis Carvalho. O que está provocando toda essa mobilização extremada é a existência, na trama do folhetim, de um casal de lésbicas idosas que, já no primeiro capítulo, se beijam e dias depois começam a preparação para o casamento, a união oficial de uma casal de quase quarenta anos de vida comum.

Não é a primeira vez que os folhetins televisivos inserem relações homoafetivas em suas tramas; mas a grande novidade é que são duas senhoras idosas, bem sucedidas, elegantes e gentis representadas por duas atrizes altamente conceituadas nos palcos teatrais e no cinema, Fernanda Montenegro e Nathália Timberg, ambas com mais de 80 anos. Em novelas anteriores esses casais em geral eram bem jovens e as relações muito mais ingênuas e românticas como soam ser as relações durante a juventude 4 .

Assim, a movimentação atual, que extrapola os meios de comunicação tradicionais e invade as redes sociais não pode deixar de ser motivo de inquietação, de reflexão sobre direitos, portanto, de cidadania. Esse caso aqui abordado é representativo de uma questão mais ampla, a da relação entre a produção de imagens e de narrativas como elementos importantes de uma disputa simbólica pela hegemonia, pela detenção do poder das falas autorizadas, legítimas, oficiais que, irão, também, conferir legitimidade - ou não - a determinadas opções sexuais.

Pode-se acreditar que a homossexualidade feminina, como no caso aqui analisado, encontra-se atravessada pelas relações de temporalidade. As relações de dominação são relações em que as de gênero e temporalidade ocupam um lugar de destaque. Como aponta Bessin e Gaudart (2009, p.2): "as categorias de idade e de sexo não são simples variáveis, mas se articulam para produzir os sistemas de poder" 5.

\footnotetext{
${ }^{3} \mathrm{Na}$ verdade, a disseminação do uso das redes sociais como meios de mobilização pública tem movimentado a cena política brasileira, colocando em confronto partidarismos opostos e manifestações no espaço público. O ocorrido em torno da novela parece um continuum dessa disposição histórica.

4 Pode-se citar outros exemplos: em 1988 a novela Vale Tudo, de Gilberto Braga, apresenta um casal lésbico: Cecília e Laís (a primeira morre logo no início); em 2003, Mulheres Apaixonadas, de Manuel Carlos apresenta duas jovens estudantes, Clara e Rafaela, que vivem uma relação homossexual;.

5 Tradução livre das autoras.
} 


\section{Poder E PROdUÇÃo discuRSIVA}

Para tentar compreender um pouco mais esse fenômeno, adota-se aqui a perspectiva que considera a esfera da produção e circulação simbólica como o âmbito em que acontece uma disputa discursiva parte de uma luta política fruto de um processo cultural e histórico para a fixação dos sentidos em uma sociedade determinada e é, simultaneamente, um lócus privilegiado de construção de subjetividades e de (re)conhecimento, por parte dos indivíduos, de suas reais condições de vida, suas possibilidades suas expectativas e histórico para a fixação dos sentidos em uma sociedade determinada.

A produção da subjetividade, nessa compreensão, não é centrada no indivíduo, mas é um processo social em que estão presentes também os espaços independentes de articulação e de circulação dos discursos hegemônicos, oficias e legítimos, assim como aqueles dissidentes ou apenas emergentes. Essa luta discursiva que opera na esfera da produção simbólica vale-se das políticas de visibilidade que são, ao mesmo tempo políticas de invisibilidade, de estratégias adotadas pelas grandes instituições produtoras de sentido, aí incluídos os meios de comunicação e as religiões.

Essa disputa expõe, com maior ou menor evidência, dependendo do momento sócio-histórico, os conflitos culturais muitas vezes latentes nas sociedades e que giram em torno de conquistas de novos espaços cidadãos, nas manifestações pela diminuição das desigualdades, pelas relações mais simétricas entre indivíduos e grupos, o que pressupõe um avanço sobre um espaço já conquistado pelas ideias (pré) estabelecidas.

As estratégias discursivas fazem uso das escolhas sobre o que e como mostrar ao público de maneira a fazer parecer naturais relações sociais arbitrárias, e a prover uma visão de mundo consensual em que prevalece a ilusão de unidade e na qual a divisão da sociedade e dos conflitos aí existentes são dissimulados, ocultados. Inserir as expressões culturais no campo da produção simbólica implica também referi-las às formas específicas como acontecem a produção e a reprodução do aprendizado das relações sociais, às formas de sociabilidade, às maneiras "adequadas" de estabelecer relações afetivas, bem como o que se espera de indivíduos em processo de envelhecimento.

As políticas de visibilidade são elementos importantes para a composição do campo das representações sociais em uma determinada época em uma sociedade. Construídas de forma particular em cada tempo e lugar, e com um caráter arbitrário, essas formas de representar indivíduos e grupos estão vinculadas às condições materiais de existência, e a diferenciação dessas condições no interior da sociedade possibilita o surgimento de conteúdos culturais e simbólicos que refletem concepções e interesses diferentes e conflitantes.

O campo da cultura e das representações simbólicas, principalmente por suas características valorativas, vai se constituir em um dos núcleos geradores de identidade para indivíduos e grupos na medida em que pode agregá-los e, ao mesmo tempo, diferenciá-los dos outros. Essas características tornam necessária não dissociar a análise das culturas das relações de poder existentes nas sociedades, porque da mesma maneira como há os discursos legitimados, naturalizados, também existem aqueles periféricos, emergentes ou mesmo marginais. 
Além disso, o campo das representações é o lugar da referência, em que indivíduos ou grupos se identificam, se percebem retratados, verificam sua existência simbólica. Por meio das formas como são representados podem se definir, ver seus desejos e possibilidades publicamente expressados. Não sem razão, os movimentos sociais em determinado momento de sua luta reivindicam a alteração nas formas de representação e exigem uma representação que seja coerente com a realidade vivida, e nesse caso podem-se citar o feminista e o movimento negro, dentre outros.

Em relação à população idosa, o psiquiatra e estudioso do processo de envelhecimento, Gérard Le Gouès (2008), enfatiza que essa representação mental de si mesmo obedece a um duplo movimento: a capacidade de adquirir qualidades e a capacidade de conservá-las. No primeiro movimento, essa capacidade de adquirir qualidades refere-se à possibilidade de identificar-se com modelos do que ser quer ser, se não realmente, ao menos no mundo ideal. Em relação ao envelhecimento, o processo de identificação é difícil, pois os modelos apresentados não são atrativos ou são menos atrativos que os da juventude. Onde estão os velhos "ganhadores" felizes, fazendo inveja, capazes de conquistas e de ser feliz? Para os velhos, não se trata de viver mais, mas de "somar vida aos anos". Não se trata, portanto, de "preservar um modo de vida juvenil, mesmo porque é ilusão, mas permitir a circulação do prazer".

No Brasil, as características culturais do País, tornam mais difícil deparar-se com o envelhecimento. É comum a referência ao Brasil como um "país jovem", numa cultura que valoriza o jovem e o novo como qualidades em si mesmos, em conseqüência envelhecer significa andar na contracorrente, em especial ao se considerar os apelos mediáticos e estéticos. A relação ente representação e construção de uma imagem positiva de si pode ser mais difícil, principalmente para as mulheres dado o uso de seu corpo como elemento de sedução. Ao homem de meia idade podem-se atribuir valores além de seu corpo físico, como maturidade, charme, poder, conquistas financeiras. Da mulher espera-se, ao contrário, "que ela permaneça sempre bela e sedutora. E, no que diz respeito ao feminino, a sedução se apoia essencialmente sobre a aparência e sobre as estratégias de valorização estética" (Lipovetsky, 2000, p. 63).

Ainda acerca do contexto brasileiro, vale ressaltar que, grande parte dos discursos difundidos pela mídia - tanto os destinados ao público mais amplo, quanto aquele específico para mulheres, aquelas que supostamente estão acima de 50 anos são sub-representadas e, quando o são, prevalecem as visões estereotipadas e/ou como indivíduos que compõem um nicho de mercado a ser explorado por determinados produtos e serviços destinados exatamente ao rejuvenescimento e ao retardamento da velhice, ou seja, retratam e tentam vender uma ilusão.

De forma semelhante, o centramento da sedução sobre o corpo, e não sobre outras qualidades como as conquistas intelectuais e/ou subjetivas, por exemplo, faz com que ela se impossibilite uma vez que o corpo suporta mal as imperfeições que a idade não tarda a lhe infligir (LE GOUĖS, 2008). Dessa maneira as experiências sexuais que se alteram como tempo são também regidas pelas questões de gênero.

A partir dessas considerações de ordem teórics, parte-se do pressuposto que a celeuma causada pelo casal de lésbicas na novela Babilônia deve-se a dois fatores capitais: 
gênero e temporalidade, aliados ao fato de ser a representação de um amor maduro e que não teme se mostrar publicamente. As observações das publicações nas redes sociais deverão fornecer elementos para demonstrar a suposição que guia esse trabalho.

\section{BABILÔNIA É AQUI!}

Embora a sinopse da novela não tenha sido divulgada pela Rede Globo, publicações disponíveis nos sites $^{6}$ da emissoa dão conta de que a trama gira em torno de três mulheres ambiciosas. Entre traições, assassínios, corrupção, prostituição entre outras mazelas sociais mostradas ao público, existe um núcleo familiar formado por duas senhoras idosas, que vivem uma união homoafetiva há quase quarenta anos. O neto de uma delas as trata como mães.

$\mathrm{Na}$ fase atual do desenvolvimento da telenovela, as duas senhoras preparam o casamento homoafetivo, há pouco tempo tornado possível legalmente no Brasil7. Os sites mencionados informam também que o beijo entre as duas personagens (fig.1), veiculado já no primeiro capítulo, não deverá se repetir, assim como a troca de carícias entre elas. Por outro lado, tórridas cenas de amor e de sexo entre casais heterosexuais são apresentadas no mesmo folhetim sem maiores pudores.

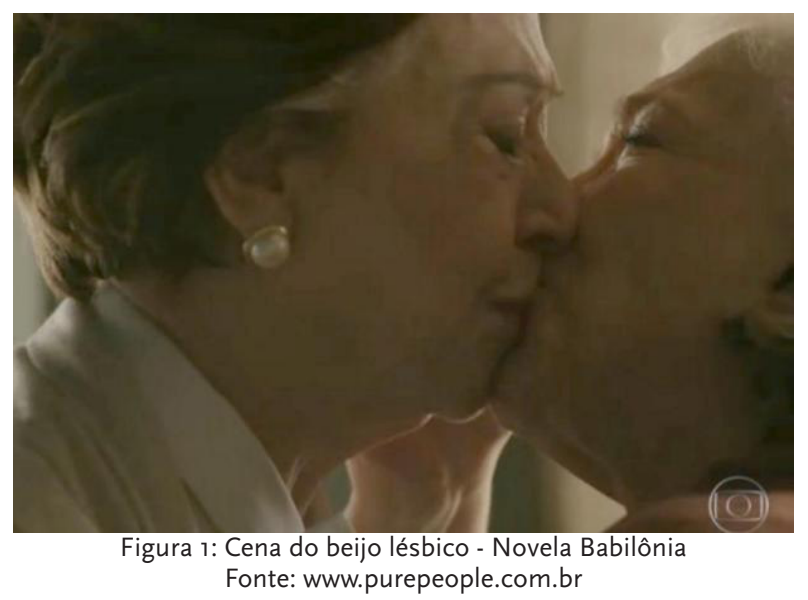

Em função disso pode-se perguntar a razão de tanto escândalo provocado pelo beijo entre as atrizes Fernanda Montenegro e Nathália Timberg, que representam personagens lésbicas. Houve disputas acirradas nas redes sociais, entre os contra e a favor, nas quais se destaca o recurso a ofensas pessoais e palavras de baixo calão. Como exemplo das publicações sobre tal polêmica, apresentamos aqui duas versões. A primeira constitui-se de trechos da nota de repúdio da Frente Parlamentar Evangélica do Congresso Nacional, assinada por seu presidente, o deputado federal João Campos, do PSDB-GO, e divulgada no dia 17 de março de 2015 (dia seguinte à exibição da cena):

\footnotetext{
${ }^{6}$ Sites como www.gshow.com.br e www.purepeople.com.br. Acesso em: 11 de abr 2015.

7 O Conselho Nacional de Justiça sentiu a necessidade de acabar com essa disparidade entre os estados que autorizam e os que não autorizam o casamento gay, e editou a Resolução $n^{\circ} 175$, de 14 de maio de 2013, publicada em 15 de maio de 2013, autorizando de uma vez por todas o casamento entre pessoas do mesmo sexo, seja por habilitação direta, seja por conversão de união estável. Fonte: www.oab-rj.jusbrasil.com.br. Acesso em: 11 de abr. 2015.
} 
A referida telenovela Babilônia tem a clara intenção de afrontar os cristãos em suas convicções e princípios, querendo trazer, de forma impositiva (...) o modismo denominado por eles de 'outra forma de amar' (...) A Frente Parlamentar evangélica convoca todos os evangélicos, todos os cristãos bem como as pessoas que se sentem violentados (sic) por estes constantes estupros morais impostos pela mídia liberal a não assistirem a novela Babilônia... recomenda que não consumam os produtos dos anunciantes que patrocinam esta telenovela.

A segunda, publicada na página pessoal da médica Emmanuelle Lira, no Facebook e amplamente repercutida (viralizada) nas redes sociais ${ }^{8}$ expõe em linguagem clara e objetiva se posicionando da seguinte forma :

"Alguns esclarecimentos importantes:

1. O casamento gay é facultativo. Ninguém no Brasil é obrigado a casar com um gay. Se você não é gay, a lei não lhe diz respeito.

2. O Beijo gay é o mesmo que qualquer Beijo. Ser gay é uma característica de pessoas, não de Beijos. Não existe Beijo negro ou Beijo gordo. Ah, também é facultativo. Ninguém é obrigado a beijar alguém do mesmo sexo.

3. A adoção de crianças por casais gays é quando um casal gay adota uma criança de um orfanato, não uma criança da sua casa. Se você não é gay e não é uma criança num orfanato, essa lei não lhe diz respeito.

4. A Globo é só uma emissora dentre muitas. Eu, por exemplo, só tenho Sky e na Paraíba a Sky não tem Globo. Ninguém no Brasil é obrigado a assistir a Novela das 9. Se assiste, é porque quer ver. Então veja.

5. Todos os programas no Brasil têm classificação indicativa. Nenhuma novela é aconselhável pra crianças de 6 ou 7 anos. Então, se você estiver preocupado com seu filho ver Beijo de novela das 9, então a Globo não é o seu maior problema. Vá ler o Estatuto da criança e do adolescente.

6. Se você é cristão, saia do Levítico e do Deuteronômio e vá ler o Sermão da Montanha e aprender o que é tolerância.

Parafraseando a Pitty: nenhuma mulher vai voltar pra co-

zinha, nenhum negro vai voltar pra senzala e nenhum

gay vai voltar pro armário. Entendam isso."

Parece que a polêmica não termina com essa postagem. Na mesma página do Facebook a médica reclama que vem sendo insultada e tem recebido mensagens: "ridículas me chamando de Bolivariana e esquerdista nojenta (como aconteceu hoje) ou mensagens dizendo que eu vou queimar no fogo do inferno porque estou defendendo homossexuais (como vem acontecendo há uns dias), eu não aceito".

${ }^{8}$ Até o momento da redação deste texto a publicação da médica em sua página teve mais de 26.000 compartilhamentos. Acesso em: 11 abr. 2015 
Em entrevista à coluna Quanto Drama! da jornalista Patrícia Vilalba, publicada no site da revista Veja de 22 de março deste ano, a atriz Fernanda Montenegro comentou com espanto as reações radicais de alguns grupos:
A situação toda está muito radicalizada na política, no comportamento. Tudo está muito extremado, e as coisas estão se radicalizando de uma for- ma muito desesperada. A reação ao beijo é moral, e a cena é julgada com a verdade divina, absoluta. Todos têm o direito de se posicionar. O problema é a radicalização desse pensar e no que ele pode se transformar. Não per- tenço aos exércitos que estão se formando por aí. Não precisamos desses exércitos. É uma caça às bruxas o que estão propondo, de todos os lados". E prossegue: "Sinceramente, não sei o que deu nesse fenômeno de revisão do comportamento. Até agora não fizemos e não vamos fazer nada que ultrapasse a lisura. Nada. E são duas personagens que ainda não se apre- sentaram totalmente. Ainda vai ser mostrado a vida dura que elas tiveram, até chegarem a esse encontro de vida comum. O beijo que está dando essa confusão toda é um beijo casto, amoroso, sem desafio erótico ou didático. É uma demonstração de carinho. Por isso, digo que não tenho capacida- de de analisar esse momento. Percebo que temos problemas muito mais graves. O país está enfrentando uma crise bastante vívida e sentida, e tem gente disposta a se voltar contra o beijo de duas atrizes de quase cem anos de idade dado dentro de uma relação sacramentada pela vida afora.

Os comentários dessa atriz são esclarecedores a respeito da polarização existente na sociedade brasileira neste atual momento. Embora ela apenas mencione a questão, não é necessário grande esforço para comprovar o poder mobilizador dos meios de comunicação e sua eficácia no cenário dos atuais protestos.

\section{Algumas considerações finais}

Por meio dos estudos dos estudos de cinema e televisão observa-se que diferentes tipos de representações referentes à temática da construção de identidades heterodoxas vêm permeando conteúdos narrativos em programas, seriados, filmes e telenovelas e contribuem para uma maior aproximação do espectador ao tema, colocando na agenda pública questões de gênero confinadas ao espaço individual.

Com sua combinação de notícia e ficção, as telenovelas acenam com a utopia de um espaço público totalmente visível aberto à interação generalizada. Como gênero mais popular da programação televisiva, passam ao largo da autoridade de família, da escola, da igreja, do Estado fazendo do controle daquilo que deve ou não deve tornar público, onde, quando e como, uma questão polêmica em si. Representam também um universo verossímil, construído de acordo com certas regras que incluem segredo e mistério, desigualdade e distorção, bem como acenam aos telespectadores interação por meio da internet favorecendo os processos de legitimidade. 
Em sua tentativa de serem incluídos no mundo real do glamour e do espetáculo, os telespectadores se apropriam do repertório da telenovela, reconhecido como comum aos brasileiros, para se posicionarem, em termos publicamente reconhecíveis, sobre questões na maioria das vezes, mas não só - afetas a modelos de comportamentos em âmbito privado.

A telenovela no Brasil tem provocado fissuras ao dialogar com a estrutura de poder a qual estamos indissociavelmente submetidos, através da repetição e da ressignificação, cada vez mais frequentes, de seres e relações comumente considerados abjetos e, em plataformas midiáticas mobilizam um processo de inteligibilidade destes grupos de pessoas. Por seu caráter, lúdico, e em função do hábito de consumo cultural, a telenovela tem sido um vetor importante na difusão de sexualidades não legitimadas pelo discurso heteronormativo, uma vez que o meio audiovisual é uma das formas de expressão que mais sinalizam publicamente estas vivencias identitárias subordinadas, involucradas no espaço privado, auxiliando na abertura de um debate político que incomoda os interesses daqueles que promovem os regimes de subordinação.

As reflexões sobre os episódios acima descritos levam a considerar ao menos dois fenômenos que não são similares, mas se complementam. Em primeiro lugar parece evidente que a sociedade brasileira passa por questionamentos de ordem ética e cultural, questionamento de valores antigos que estão sendo postos em xeque, como uma busca por práticas de vida pessoal e pública de maneira mais ética. Ao menos esse é o discurso oficial, não uma garantia de que seja seguido. Ainda que associado a um certo conservadorismo nos costumes, esse discurso tem se popularizado e se tornado "senso comum". Se por um lado, há o elogio da ética, por outro a transformação em "senso comum" impede questionamentos e discordância em relação a eventuais desdobramentos na cena política e cultural.

Em outro sentido, pode-se pensar que o país vem passando por uma grande evolução no campo institucional, com legislação que favorecem categorias e grupos minoritários, como por exemplo, o avanço das leis trabalhistas para o emprego doméstico e regulamentação das uniões homoafetivas, e um retrocesso no campo cultural-ideológico.

A intolerância e a polarização não estão localizadas apenas no campo religioso; aparentemente instituições tradicionais como a família, que vem sendo repensada e reconstituída, em diversos formatos, transformando-se no que atualmente se denomina como "arranjos conjugais" parecem ameaçar a estabilidade da instituição nos moldes tradicionais ou heteroafetivos. Esses dois fenômenos permitem compreender um pouco a repulsa causada pela representação de afeto entre duas mulheres idosas. Às assimetrias de gênero somam-se as da idade. Ou seja, com a idade agravam-se as desigualdades e os preconceitos contra a mulher.

\section{REFERÊNCIAS}

Aumont, J. (1995). A estética do filme. São Paulo: Ed. Papirus.

Barker, A. D. (2004). The power and persistence of stereotyping. Aveiro, Portugal: University Aveiro Press. 
Beauvoir, S. (1990). A velhice. Rio de Janeiro, Brasil: Nova Fronteira.

Bessin, M. e Goudat, C (2009). Les temps sexués de l'activité: La temporalité au pricipe du genre? Revue Temporalités, 9. Acedido em http://temporalites.revue.org/

Ben, H. (2004). The everyday life reader. Londres, England: Routledge.

Bosi, E. (1987). Memória e sociedade - lembranças de velhos. São Paulo: T.A. Queiroz/ Edusp.

Butler, J. (2003). Problemas de gênero: feminismo e subversão da identidade. Rio de Janeiro, Brasil: Civilização Brasileira.

Colling, L. (2007). Personagens homossexuais nas telenovelas da Rede Globo: criminosos, afetados e heterossexualizados. Revista Gênero, 8(1), 207-222.

Felski, R. (1995). The gender of modernity. Cambridge, England: Harvard University Press.

Filho, J. F. (2005). Força de Expressão: construção, consumo e contestação das representações midiáticas das minorias. Revista FAMECOS, 28, 18-29.

Giddens, A. (1992). A transformação da intimidade: sexualidade, amor e erotismo nas sociedades modernas. São Paulo: Editora Unesp.

Hall, S.(2006). A identidade cultural na pós-modernidade. Rio de Janeiro: DP\&A Editora.

Hall, S.(2006). Da diáspora: identidades e mediações culturais. Belo Horizonte: Editora UFMG/UNESCO.

Hamburger, E. (1998) Diluindo fronteiras: a televisão e as novelas no cotidiano. In L-M- Schwarcz, (Org.), História da Vida Privada no Brasil: Contrastes da Intimidade Contemporânea (pp.439-87.). São Paulo: Companhia das Letras, v.4,

Jakubaszko, D. (2010). A construção dos sentidos da masculinidade na telenovela a favorita: um diálogo entre as representações da masculinidade e as manifestações discursivas do ambiente social brasileiro. Tese de doutorado. Escola de Comunicação e Artes, Universidade de São Paulo - USP.

Le Gouès, G. (2008). La représentation du corps vieux. Paris: Puf.

Lipovetsky, G. (2000). A terceira mulher: permanência e revolução do feminino. S. Paulo: Cia das letras.

Lopes, D. et al (2004). Imagem e diversidade sexual: estudos da homocultura, Brasília: Nojosa.

Lopes, M. I.; Borelli, S. H.; Resende, V. (2013). Vivendo com a telenovela: mediações, recepção teleficcionalidade. São Paulo: Summus.

Maggio, S.; Quelem, N. (2003). A namorada tem namorada. Correio braziliense, Brasília, 25 mai. Acedido em http://www2.correioweb.com.br/cw/edicao_20030 525/sup_tv_250503_57. htm.

Mendonça, M. L. M; Ferreira, C. (2014). Envelhecimento feminino, consumo e protagonismo. É a (voz da) vovozinha! .Revista Comunicação, Mídia e Consumo, 14, 119-136.

Montoro, T. (2009). Velhices e envelhecimentos na cinematografia mundial. In: Mendonça. M. L. M. (org.) Mídia e diversidade cultural. UFG, Goiânia: Editora Casa das musas. Programa de Pós Graduação em Comunicação e Cultura.

Montoro, T. S.; Senta, C. R..M. D. (2014). A dança da vida no limiar da morte: exercícios transgressores da feminilidade na velhice. Labrys études féministes/ estudos feministas, janeiro/junho. Acedido em http:// www.labrys.net.br/labrys25/cine ma/montoro.htm 
Montoro, T.; Ferreira, C. (2014). Mulheres negras, religiosidades e protagonismos no cinema brasileiro. Galáxia, 27, 145-159. Acedido em http://revistas.pucsp.br/index.php/galaxia/article/view/16147/1454

Montoro, T. (2009). Protagonismos de gênero nos estudos de cinema e televisão no país. Revista Lumina, 2 , (3), 01-18.

Montoro, T. (2013). Estudos de recepção do audiovisual na interface com estudos de gênero e crítica feminista. In M. Bamba (Org.) A Recepção Cinematográfica: Teoria e Estudos de Caso (pp. 67-85). Salvador, EDUFBA,

Schwarcz, L. M. (1993). O espetáculo das raças: cientistas, instituições e questão racial no Brasil 1870-1930. São Paulo: Companhia das Letras.

Scorsolini-Comin, F.; Santos, M. A. D. (2012). Insensatos afetos: homossexualidade e homofobia na telenovela brasileira. Barbarói, (36), 50-66.

Silva, T. T. da. (2000). A produção social da identidade e da diferença. In T. Silva (Org.), Identidade e Diferença: A Perspectivas dos Estudos Culturais (pp.73-102). Petrópolis: Editora Vozes,

Swain, T. N. (2006). Entre a vida e a morte, o sexo. Labrys études féministes/ estudos feministas, Brasília, 12, 1-10.

Tânia Siqueira Montoro é doutora em Comunicação Audiovisual pela Universidad Autonoma de Barcelona com Pós doutorado na Deustch Film Institute, Holanda. Professora e membro do Programa de Pós Graduação da Faculdade de Comunicação da Universidade de Brasília.

E-mail: taniamontoro@unb.br

Universidade de Brasília / Universidade Federal de Goiás Campus Universitário Darcy Ribeiro, Brasília - DF, 70910-900Avenida Esperança, s/n - Setor Itatiaia, Goiânia GO, 74690-900 Brasil

Maria Luiza Martins de Mendonça é doutora em Comunicação, pesquisadora, professora associada e membro do Programa de Pós Graduação da Faculdade de Informação e Comunicação da Universidade Federal de Goiás.

E-mail: mluisamendonca@gmail.com

Universidade de Brasília / Universidade Federal de Goiás Campus Universitário Darcy Ribeiro, Brasília - DF, 70910-90oAvenida Esperança, s/n - Setor Itatiaia, Goiânia GO, 74690-900 Brasil 